4. David TE, David CM, Tsang W, Lafreniere-Roula M, Manlhiot C. Long-term results of mitral valve repair for regurgitation due to leaflet prolapse. J Am Coll Cardiol. 2019;74:1044-53.
5. Suri RM, Schaff HV, Dearani JA, Sundt TM, Dalcy RC, Mullany CJ, et al. Survival advantage and improved durability of mitral repair for leaflet prolapse subsets in the current era. Ann Thorac Surg. 2006;82:819-26.
See Article page 1087.

\section{Commentary: In the hands of the experienced, do not fear anterior leaflet pathology}

\author{
Makoto Mori, MD, and Arnar Geirsson, MD
}

With the rapid advancement of transcatheter alternatives to surgical approaches, the surgical community bears the responsibility of optimizing surgical outcomes to provide a fair benchmark against which novel, less-invasive approaches can be compared. Mitral valve repair is one of such operations that has a significant margin for advancement, both via system-level strategies for volume regionalization ${ }^{1}$ and technical-level improvement to optimize the outcomes inherent to the operation itself.

Brescia and colleagues ${ }^{2}$ address the latter aspect in this study by demonstrating that repair of anterior leaflet pathologies, which are repaired less frequently compared with posterior pathologies, may achieve excellent outcomes. In their single-center series, authors reported that the survival and freedom from reoperation were not significantly different between isolated anterior or bileaflet repair versus posterior leaflet repair. The finding is thought-provoking, because anterior leaflet pathology has historically suffered from lower rates of repair, likely owing to existing evidence suggesting that they are less durable. ${ }^{3}$ The report is an encouragement to not discard the repair option solely based on the presence of an anterior leaflet pathology.

The excellent outcomes should be contextualized to the fact that the operations were performed in a highly

\footnotetext{
From the Section of Cardiac Surgery, Yale University School of Medicine, New Haven, Conn.

Disclosures: Authors have nothing to disclose with regard to commercial support.

Received for publication Dec 1, 2019; revisions received Dec 1, 2019; accepted for publication Dec 2, 2019; available ahead of print Dec 17, 2019.

Address for reprints: Arnar Geirsson, MD, Section of Cardiac Surgery, Yale School of Medicine, BB204, 330 Cedar St, P.O. Box 208039, New Haven, CT 06510 (E-mail: arnar.geirsson@yale.edu).

J Thorac Cardiovasc Surg 2021;162:1098-9

$0022-5223 / \$ 36.00$

Copyright (c) 2019 by The American Association for Thoracic Surgery

https://doi.org/10.1016/j.jtcvs.2019.12.005
}

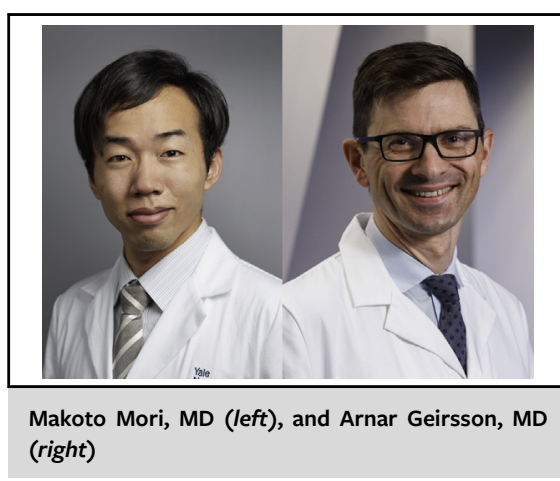

CENTRAL MESSAGE

In experienced hands, anterior

leaflet pathology may be repaired

effectively and safely. The presence

of an anterior leaflet pathology

alone should not limit repair op-

tions in a specialized setting.

specialized setting, with one surgeon operating on the majority $(85.3 \%)$ of this series. Presumably, anterior leaflet repair was performed at an even greater proportion by this operator. Therefore, this report demonstrates what can be achieved in a highly specialized condition, rather than widely generalizable outcomes of anterior versus posterior leaflet repair. Technical complexity of anterior repair would suggest that the 25 repairs/year surgeon volume threshold reported previously ${ }^{4}$ is likely greater when specifically considering anterior leaflet repair.

Caution must be exercised in interpreting the reported nonsignificant difference in the risk of reoperation, as David and colleagues ${ }^{5}$ demonstrated in a single-surgeon series that isolated anterior leaflet prolapse was a significant predictor of recurrent mitral regurgitation and reoperation during the median follow-up of 10 years. ${ }^{5}$ This may be in line with the competing risk analysis by the authors that also showed a nonsignificant but a greater cumulative incidence of reoperation in the anterior repair group $(7.5 \%$ vs $4.9 \%){ }^{2}$ Regardless, repair with an increased risk of reoperation 
may still yield survival and other outcomes favorable to those of replacement. Taken together, the report encourages expanding repair options to anterior leaflet pathologies at centers of excellence.

Under rigorous evaluation of comparative effectiveness between surgical and less-invasive alternatives, it is all the more critical that the surgical community fulfills the maximal benefit that surgical approach can offer. The authors must be congratulated for challenging the conventional wisdom and encouraging us to critically evaluate potential options for repairing anterior leaflet diseases.

\section{References}

1. Vemulapalli S, Grau-Sepulveda M, Habib R, Thourani V, Bavaria J, Badhwar V Patient and hospital characteristics of mitral valve surgery in the United States. JAMA Cardiol. 2019;4:1149-55.

2. Brescia AA, Watt TMF, Rosenbloom LM, Murray SL, Wu X, Romano MA, et al Anterior versus posterior leaflet mitral valve repair: a propensity-matched anal ysis. J Thorac Cardiovasc Surg. 2021;162:1087-96.e3.

3. Gillinov AM, Blackstone EH, Alaulaqi A, Sabik JF III, Mihaljevic T, Svensson LG, et al. Outcomes after repair of the anterior mitral leaflet for degenerative disease. Ann Thorac Surg. 2008;86:708-17.

4. Chikwe J, Toyoda N, Anyanwu AC, Itagaki S, Egorova NN, Boateng P, et al. Relation of mitral valve surgery volume to repair rate, durability, and survival. J Am Coll Cardiol. April 24, 2017 [Epub ahead of print].

5. David TE, Armstrong S, McCrindle BW, Manlhiot C. Late outcomes of mitral valve repair for mitral regurgitation due to degenerative disease. Circulation. 2013; $127: 1485-92$. 